\title{
Lazaretos, historia y proyectos en la Real Academia de Bellas Artes de San Fernando (I) ${ }^{1}$
}

\author{
Juana María Balsalobre García²
}

\begin{abstract}
RESUMEN
ABSTRACT

Las epidemias en las ciudades del siglo $x i x$ han sido estudiadas en Epidemics in the cities of the 19th century have been the subject of múltiples trabajos y con diversas $e$ interesantes perspectivas. También hay algunas sobre lazaretos, pero la

que aqui se presenta tiene como enfoque singular, el hecho de intentar establecer relaciones, en unas circunstancias históricas, con los planteamientos arquitectónicos teóricoprácticos del edificio llamado lazareto.

Gracias al análisis de unas fuentes documentales inéditas, que tienen una indudable importancia para acercarnos

a la visión de la época y a la del edificio. Especialmente de las últimas many studies which have diverse and interesting perspectives. There are also some (STUDIES) about lazaretos, but the one presented here, has as its main focus, the possible link between historical events and theoretical-practical architecture. It is through the analysis of valuable unpublished documents, that we can achieve a better understanding of that time and of the building. Especially of the end of the $18^{\text {th }}$ and the beginning of the $19^{\text {th }}$ centuries.
\end{abstract} décadas del siglo xvil y las primeras

La génesis de este estudio se halla en una de las investigaciones paralelas a la que fue mi tesis doctoral de donde se toman lógicamente los nexos metodológicos. Pensado como un conjunto pero, debido a su extensión, se ha dividido en dos partes, la primera recoge básicamente lo que se analiza en este escrito y la segunda se trata en un segundo artículo, también para esta revista.

2 Centro Asociado a la UNED de Elche-Alcoy. 


\section{INTRODUCCIÓN}

Históricamente se hace referencia a que el nombre de Lazareto vendría dado por la función de aislamiento que tuvieron las leproserías conocidas como hospitales para los enfermos de lepra «dolencia de la cual se supone murió Lázaro milagrosamente resucitado, luego beatificado y del cual tomaron el nombre ${ }^{3}$. La finalidad de ese tipo de recintos ya se establecía en la Biblia, subrayando la idea de aislar a los enfermos contagiosos según el grado en cuarentena temporal, de siete a catorce días o secuestración definitiva. También se menciona cómo desde Jerusalén, y a través de los cruzados, pasó a Europa el concepto de lazareto e igualmente las diversas enfermedades.

Asimismo hay que referirse a la acepción en relación con lo arquitectónico. Se llama lazareto a un recinto aislado y cercado, donde se insertan diversos pabellones o construcciones más o menos separadas. Su finalidad es, primero, la de acoger a las personas y mercaderias, que llegan de lugares infectados por el contagio de esos sitios y a la de personas 0 cosas a las que se han acercado, y segundo que, una vez en ese lugar, sean observados, según la patente ${ }^{4}$, durante un cierto periodo de tiempo.

El tema es muy interesante y debido a los eslabones que lo conforman es asimismo amplio por lo que aqui, se trata de exponer una sintesis de lo estudiado. Se estructura de una forma abierta, en dos partes, totalmente interdependientes con un elemento común, el lazareto. La primera se refiere a una visual, que muestre lo histórico de la acepción y sus relaciones científico-sanitarias. La segunda se centra en lo que expresan algunos autores de los proyectos dentro de un planteamiento arquitectónico, geográfico y cronológico, que reflejan unas particularidades y otros aspectos interesantes a destacar.

Por otra parte, se quiere señalar que la elección de los ejemplos gráficos no ha sido aleatoria, pues debido a la concreción mencionada al principio, se establece la prioridad cronológica. Así, se incluyen las láminas de algunos planos de los Lazaretos señalados para Madrid y también de otro Lazareto, en alto, firmado por el madrileño, José Paris. Este arquitecto no indica el lugar geográfico concreto, pero si menciona como situación la próxima a la costa y en lugar seguro para los buques. Son las memorias

\footnotetext{
3 Archivo de la Real Academia de Bellas Artes de San Fernando (AASF) Legajo 14-6/2. José Ramón Mas. Memoria descriptiva de un Lazareto en puerto de mar. Madrid 18 de marzo de 1854.

4 Era un tipo de pasaporte sanitario, que, se clasificaba en cuatro tipos: limpia, sospechosa, tocada y sucia. Se tratará en el siguiente apartado de la visual histórica del lazareto.
} 
facultativas y los planos, que se hallan en el Archivo y Gabinete de Planos de la Academia de Bellas Artes de San Fernando, la fuente documental, y ésta es el hilo conductor de la segunda parte del tema. La influencia y el papel desempeñado por esta institución madrileña, ha sido muy destacada, y expresada en recientes estudios, no solamente por su trascendencia artística sino también por sus vinculaciones y su imagen de la época ${ }^{5}$.

Todo ello permite establecer unos enlaces con la arquitectura y aquellos principios implícitos, que destacan, como las preocupaciones higienistas, que ocupan a teóricos, arquitectos, médicos, autoridades, etc. Hay unas referencias claras respecto a la limpieza de las ciudades, contemplada claramente desde la Antigüedad Clásica y expresada por tratadistas. Plantean esa correspondencia entre el trazado de puertas, calzadas, calles, y las alcantarillas, porque ayudan a prevenir la contaminación del aire de miasmas y gérmenes. La teoría miasmática preconizada por Hipócrates (460 a. C.-377 a. C.), en su tratado "De los aires, aguas y lugares" sugiere que esos factores son fundamentales para la salud.

En los siglos del Renacimiento y especialmente con la llustración se defendieron una serie de teorias higienistas relacionadas con los males sociales y las ciudades, que el siglo XIX, con nuevos conocimientos médico-científicos, también utilizó. Las referencias a aquella ciudad cerrada dentro de las murallas, maloliente, sucia, con el ambiente enrarecido y el aire viciado, resultaban preocupantes para las instituciones de salud pública y sus vecinos. Aquellos postulados se planteaban con más o menos fuerza, según se tratase de enfermedades -endémicas- o epidemias. En las primeras, se señalan, entre otros factores, las condiciones geográficas de determinados lugares, como por ejemplo las aguas estancadas, que provocaban el paludismo, y en las epidemias se cuestionaban otros muchos problemas como el de la movilidad de visitantes, comerciantes, y marineros, que recibía la ciudad, si era puerto de mar.

Junto a las circunstancias expresadas se daban otros graves problemas socio-sanitarios como, cuando las instituciones declaraban oficialmente que, había una epidemia como la fiebre amarilla -llamada también enfermedad de Siam, vómito negro o fiebre marinera-. De lo que no cabe duda es de la intención de mejorar. Conviene recordar que la relación con el comercio marítimo es clara y, además en las Reales órdenes,

\footnotetext{
5 Entre los investigadores de los fondos del Archivo de la Real Academia de San Fernando. quiero mencionar a mi maestro, José Enrique Garcia Melero, que, además de publicar relevantes estudios acerca de la Academia de San Fernando, también ha analizado la tipología arquitectónica de la cárcel y la de los puentes, en esa institución de las Bellas Artes.
} 
se regulaba la normativa a seguir al llegar a los puertos "sanos". Si los barcos arribaban de los Estados Unidos de América se les mandaba hacer cuarentena de observación. Asimismo, según fuese de sospechosa su procedencia, y el tiempo transcurrido, desde la salida del puerto, se determinaba la mencionada observación por doce, veinte, treinta o cuarenta días para que no hubiese contagio.

Dentro de ese contexto se planteó la construcción de esos lazaretos, uno de los ejemplos edificados fue, para el comercio con el Mediterráneo, el de Mahón, que se comenta más adelante. No obstante, en muchas de las ciudades portuarias se habilitaban o se ocupaban recintos, que no tenían esa función pero que la necesidad obligaba. Estaban, normalmente fuera de las murallas, y particularmente eran: conventos, casas de campo y otros, habilitados como una especie de campamentos ubicados en áreas de campo o huerta.

Las precauciones tomadas por las autoridades higiénico-sanitarias imponían, a más de separar a los enfermos, y aislarlos. También, establecer unos cordones sanitarios para evitar contagios. Aunque, a las tan repetidas deficencias higiénicas se sumaban otros factores económico-sociales, que complicaban o determinaban a veces el origen de una epidemia. Se deben mencionar elementos como el contrabando y el fraude en las aduanas, no solamente, desde un aspecto económico y júridico - no se cumplían las Reales Órdenes-, sino por los problemas relacionados con la higiene y la salud. Cabe señalar una premisa, bastante repetida en el $x \mid x$; el inicio de una epidemia se relacionaba con la llegada de viajeros y barcos con géneros infectados.

\section{UNAS VISUALES HISTÓRICAS DEL LAZARETO}

En la introducción se exponía como la historiografía establecía el nacimiento del lazareto, por un lado en su función, que el aislamiento determinaba en los hospitales destinados a los enfermos de lepra, llamados leproserías ${ }^{6}$, y por otro la acepción sustantiva a Lázaro, que la padeció, murió, y fue milagrosamente resucitado. La fuente escrita es la Biblia y ya se expresaba la necesidad de aislar a los enfermos contagiosos, según el grado, en cuarentena temporal o definitiva. La cuestión también se rela-

\footnotetext{
6 Bosch Millares, J. “El Hospital de San Lázaro, de Canarias su primer emplazamiento " en MEDICINA E HISTORIA Centro de Documentación de Historia de la Medicina de J. Uriach \& Cía. S.A., N. ${ }^{\circ} 43$, Barcelona, febrero 1975.
} 
ciona con el comercio en las costas del Mediterráneo y con las cruzadas medievales a Jerusalen.

En el siglo xv algunos lazaretos fueron establecidos, por los gobiernos europeos, cuando se desataban las pestilencias, pero las situaciones y los efectos provocados por la peste continuaron. No obstante, en 1720 a raíz de la peste de Marsella, la monarquía borbónica trató de establecer, una serie de medidas, "frente al sistema tradicional de defensa caracterizado por la improvisación, la fragmentación y el clericalismo (la Iglesia soportaba el peso de la asistencia a los apestados), se alza un nuevo sistema: estable, centralizado, laico y burocrático. Se crea una Junta Suprema de Sanidad, que dicta y hace cumplir enérgicas medidas para prevenir el contagio: cierre del comercio con Francia, vigilancia de costas; los buques y puertos son sometidos a control especial y se instaura un completo sistema de lazaretos y cordones sanitarios"s?

A partir de aquel año la preocupación, ante el grave problema, determinó la acción de las monarquias europeas ${ }^{8}$ y la labor de estudiosos que, trataron el tema, como John Howard en su obra, An Account of the Principal Lazaretos in Europe, publicada en Inglaterra el año 1789, e igualmente conocida en nuestro país por traducciones al francés, por ejemplo la de París 1801 Histoire des principaux lazarets de l' Europe. El tratadista inglés estudia además otros edificios, y analiza entre otros los lazaretos de Marsella y Génova. Asimismo hemos de referirnos al Recueil del francés J. N. L. Durand, obra publicada en París el año 1801, además de otras tipologías como la del teatro, reproduce un plano del Lazareto de Milán.

Históricamente, aparte de los asuntos políticos, económicos, sociales, que condicionaban el comercio maritimo, se daban otros relacionados con ese tráfico. Era el miedo, tanto de los tripulantes de los barcos, a visitar puertos sospechosos o apestados, como de las ciudades portuarias a tener esos problemas. Institucionalmente regulado, tras la peste ${ }^{9}$ que en

URTEAGA, L. «Miseria, miasmas y microbios. Las topografias médicas y el estudio del medio ambiente en el siglo Xix" en Geocrítica, Universidad de Barcelona, año $V$, número 29, noviembre de 1980, pág. 9, donde se refiere al estudio de J. L. y M. PESET cuando canalizan las medidas tomadas por la Monarquía Borbónica para enfrentar la peste (1978, 7-28).

8 "Los inicios en la segunda mitad del siglo xvill, de una "politica de la salud impulsada por los estados absolutistas e instrumentalizada a través de las sociedades científicas, y las nuevas demandas sociales que imponen el impacto de entermedades endémicas y nuevas epidemias (fiebre amarilla y cólera), constituyen el marco institucional y social respectivos, que pueden ayudarnos a explicar el éxito de los "enfoques ecoiógicos" en la medicina». URTEAGA, ob. cit., pág. 8.

Carreras Panchón, A. Miasmas y retrovirus. Cuatro capitulos de la historia de las entermedades transmisibles, Fundación Uriach 1838, Colección Histórica de Ciencias de la Salud. Barcelona, 1991. 
1720 arrasó Marsella, por Reales Disposiciones que "crean la "Carta o Fe de Sanidad", patente que se otorgaba en los puertos de salida a aquellas que acreditaban suficientemente su salubridad... por Real Cédula del 10 de octubre de 1721, establecida por consulta de la Junta de Sanidad, se prescriben los requisitos que deberán cumplir las patentes de sanidad" 10 había que detallar los nombres del patrón del barco, de los marineros, así como la fecha y el puerto de salida e igualmente las escalas.

Efectuada la observación, cumplida la cuarentena y determinada su limpieza, ya podían circular libremente por la ciudad. Respecto a los géneros o mercancías también permanecian depositadas para ser ventiladas e igualmente desinfectadas, en los lugares determinados, y así cumplir las Reales Órdenes establecidas para el resguardo de la salud pública. En aquellas Reales disposiciones se plasmaron las diversas propuestas de teóricos y científicos y otras más locales trataron de determinar los procedimientos y las pautas más adecuadas. Por ejemplo en Mahón e isla de Colom con la cuarentena de esclavos ${ }^{11}$, en Barcelona, por la misma impuesta al turco, señor Ahmed Vasif Effendi y su acompañamiento. ${ }^{12}$

Los reglamentos ${ }^{13}$, lógicamente relacionados con las circunstancias de la época se singularizan por lo que expresan, así la Comisión encargada de los Reglamentos de Sanidad sobre los Lazaretos de observación y cuarentenas expone que "no ha perdido de vista un momento, que la salud publica es la suprema ley de todas las personas civilizadas... No ignora la

10 Carreras Roca, M. “El Lazareto de Mahón de Manuel Rodríguez de Villalpando" en Medicina e Historia, Segunda época, Centro de Documentación de Historia de la Medicina de J. Uriach \& Cía., n. ${ }^{\circ}$ 40, Barcelona, noviembre 1974, págs. 13-14. GiménEZ LÓPEZ, E. "Alicante ante la peste de 1720", Canelobre, 4, págs. 98-104.

11 "Plan de la isla dicha de Colom que dista dos leguas de Mahon. Está destinada para la quarentena de los esclavos, venidos en barcos del capitán Escudero ... Mahón, 28 de abril 1787" León Tello, P. Mapas, planos y dibujos de la sección de Estado del Archivo Histórico Nacional. Madrid, Ministerio de Cultura, 1979, pág. 65.

12 Ibidem, pág. 23 «Plano que demuestra la casa de lazareto de esta ciudad, las barreras que se han puesto en el circuito y demás precauciones últimamente tomadas para hacer quarentena el señor Ahmed Vasif Effendi y su acompañamiento" Siguen explicaciones topográficas. Pertenece a la correspondencia del conde de Asalto con el de Floridablanca sobre la cuarentena impuesta a todo barco procedente de Levante, y con motivo de la llegada del enviado turco. Por Carlos Francisco Cabrer. Barcelona, 8 de agosto 1787».

13 Discurso preliminar del reglamento de los Lazaretos de Observación. Siglo XVIII. En el Archivo de la Real Academia de Bellas Artes de San Fernando AASF. Disertaciones, 314-3/3. En el mismo legajo "Reglamento del Expurgo de los pueblos inficionados y de los géneros y efectos procedentes de ellos, $y$, Reglamento para los Lazaretos de observación destinados a los pueblos mientras reynan las enfermedades pestilenciales. Otra cuestión que interesa destacar es la solución que se intentaba dar respecto a las teorias miasmáticas, con la Real Cedula expedida en Madrid a 3 de abril de 1787 mandando restablecer el uso de cementerios ventilados para sepultar los cadáveres de los fieles, Madrid, Pedro Martín, 1787. 
Comisión la mucha delicadeza y riesgo que hay en interrumpir el giro regular del comercio, lo que solo debe practicarse en casos apurados y extremados y que el rigor intempestivo superfluo y las providencias excesivamente severas no solo producen descalabros en el comercio y aborto de los pueblos, sino infinitas torsiones... la Comisión ha cuidado de no presentar a la Junta Municipal de Sanidad ley alguna que no tenga en su abono el partido menos ambiguo y mas prudente o seguro en los casos dudosos, el resultado de las observaciones de los médicos prácticos mas recomendables acerca de la naturaleza y propiedades de la fiebre amarilla, de la que se trata de conservar a Madrid y al resto de la península... procurando evitar siempre el demasiado rigor, o las providencias intempestivamente severas e impeditivas del comercio necesario y no dañoso con los pueblos contagiados, como también la sobra y exceso de atención a los intereses mercantiles al termino de arriesgar la salud de los pueblos. Antes de proceder a establecer este Reglamento determinemos primero si es o no contagiosa la fiebre amarilla" ${ }^{14}$. También se refiere a otros decretos como los dados en en los años 1801, 1802, 1803, 1804 y 1808 . A principios del siglo XIX, debido a aquellos graves problemas socio-sanitarios se establecieron las Juntas de Sanidad locales, que tuvieron un extraordinario interés, especialmente por la labor de sus individuos, al observar la situación para tratar de dar y determinar soluciones ${ }^{15}$.

Si todas las arquitecturas dependen de unos condicionantes específicos como promotor, arquitecto e incluso época, las del grupo relacionado con la Salud Pública tienen unas particulares connotaciones, que sobrepasan el concepto de edificio y se conjugan con su funcionalidad. La cuestión teórico práctica es amplia e interesante, dentro de los estudiosos del tema se hallan algunos médicos, que han destacado como individualidades especiales en nuestras ciudades históricas. Por ejemplo, del tema que ahora nos ocupa, se puede mencionar una interesante obra, publicada el año 1813, El Lazareto de Maón o Memoria Descriptiva de sus obras Reflexiones

\footnotetext{
14 Ibidem. Discurso preliminar del reglamento de los Lazaretos de Observación, donde también se refiere a los Decretos de 1801, 1802, 1803 y 1804

15 "A principi del segle XIx, entre 1800 i 1803, es van declarar epidèmies a Andalusia, limitades a Cadis, Màlaga, i Sevilla. El govern es va posar en alerta i des de la Junta Suprema de Sanitat es van dictar les mesures per evitar-ne l'expansió... Segons els documents de l'època, les mesures preventives consistien a aillar les poblacions mitjançant cordons sanitaris, confinar les persones en llatzerets, imposar quarentenes i emprar diversos vapors quimics destinats a fumigar els llocs contaminats, a fi de neutralitzar la causa de la malaltia. Un complicat sistema de passaports de sanitat regulava el trànsit de les persones mentre les embarcacions eren sotmeses a inspecció i si calia s'ordenava la quarantena". PAscual Artiaga, M. Fam, malaltia i mort. Alacant Ila febre groga de l'any 1804, La Xara, Simat de la Valldigna, 2000, págs. 12-13.
} 
críticas sobre su estado actual y proyecto para que sea general y el puerto franco en beneficio del comercio del Mediterráneo que por lo que puede convenir, antes de arreglarse el ramo de Sanidad, dedica al poder legislativo Manuel Rodriguez ${ }^{16}$. Ese Lazareto tenido como modelo, a pesar de las circunstancias históricas, fue proyectado y construido ${ }^{17}$ entre las últimas décadas del siglo XVIII y la primera del XIX. Sin embargo, los problemas causados por la Guerra de la Independencia (1808-1814), las cuestiones político-institucionales y las dificultades económicas fueron factores que impidieron o no permitieron levantar otros proyectos interesantes.

No obstante, es necesario subrayar que el interés por la Higiene pública general siguió ocupando a las instituciones ${ }^{18}$ y a figuras claves, como Pedro Felipe Monlau, Doctor en Medicina y Cirugía; Consejero de Sanidad ... y autor de diversas obras sobre el tema con una primera edición en el año 1847 de su obra Elementos de Higiene Pública o Arte de Conservar la Salud de los Pueblos, que fue libro de texto en las Facultades de Medicina. Aquí, se quieren mencionar algunas de las aportaciones relacionadas con los lazaretos puesto que son muy clarificadoras. Se planteaba como base que las precauciones contra la importación de los contagios deben empezar en el mismo origen de estos, por ello era necesario que en los puertos los responsables sanitarios diesen una especie de pasaporte sanitario o patente de sanidad ${ }^{19}$

${ }_{16}$ Estudiado por el Dr. Manuel Carrefas Roca. "El Lazareto de Mahón de Manuel Rodriguez de Villalpando" en Medicina e Historia, Segunda época, Centro de Documentación de Historia de la Medicina de J. Uriach \& Cía., n. 40, Barcelona, noviembre 1974, págs. I-XVI.

17 Sambricio, C. La Arquitectura española de la llustración. Madrid, Instituto de Administración: Local, 1986. En su estudio señala que Casanova en 1796 es comisionado, junto con Martin Rodriguez para inspeccionar el Lazareto de Mahón, que Justo Pellón habia concebido poco antes. En las Actas de la Comisión de Arquitectura de la Real Academia de Bellas Artes de San Fernando n. 124, 31 de marzo de 1796. "Además de los planos presentados por Santiago Sebastian en su estudio sobre Mallorca. hemos encontrado entre los fondos del Archivo Histórico Militar de Madrid la documentación correspondiente al proyecto de Pellón. Miguel Pellón Planos del Lazareto de Mahón B/17-8. B/17-1. B/15-18 que corresponden respectivamente a los núms 3609, 3602 y 3588 del nuevo catálogo, pág. 316, nota pie página 24 y pág. 317.

18 Instrucción del 18 de julio de 1817 para la expedición, revisión y refrendo de las patentes de Sanidad. Instrucción para declarar el contagio de peste, ó de otra mortifera enfermedad, en alguna población del reino, y preservar a las demás de su maligno acceso; redactada por la Junta Suprema de Sanidad, y aprobada por S.M. en 25 de agosto de 1817, y, otras reales disposiciones.

19 Pedro Felipe MonLaU, ob. cit. Las patentes "deben ser uniformes, impresas, infalsificables, numeradas, y expresar el nombre del buque y el de su comandante, capitan ó patron; su cabida; el puerto de su procedencia; el estado de salud que en él se ha disfrutado y se disfruta el día del otorgamiento; si en él hay o no establecido servicio de sanidad; el estado higiénico del buque; la naturaleza del cargamento; el número de la tripulacion, el de pasajeros y el estado de su salud... Iguał patente se expedirá a todas las embarcaciones que salgan de nuestros puertos para los extranjeros (con intervención de los respectivos cónsules), o para los de nuestras colonias pág. 228. 
a todas las embarcaciones, nacionales o extranjeras, mercantes o de guerra, que naveguen para los puertos de España en ambos hemisferios.

Respecto a las patentes limpia, tocada, sospechosa, y sucia, analiza, en ese orden, por la salud o el contagio en el lugar de salida. Alli, el cónsul o responsable español debía visitar o mandar visitar el barco de salida para cumplir los reglamentos sanitarios, que también se debían respetar en la travesía. Además el comandante, capitán o patrón, tenía que anotar en el diario de navegación todas las situaciones e incidencias habidas durante la travesia. Aquel diario sanitario recogia, y de ahi su gran interés, los posibles cambios en las patentes, según las relaciones con otros buques o escalas en otros puertos.

Asimismo, las embarcaciones, en el mar, debían dar a conocer la patente con la que navegan: limpia - bandera blanca-, tocada - bandera amarilla - sospechosa - bandera amarilla y negra en su longitud-y para la sucia o apestada - amarilla con un globo negro en el centro-. No obstante, los que llevasen esta última, si es por la noche tenían que llevar un farol encendido, al final de uno de los palos, para dar a conocer su situación y estado sanitario.

En cuanto a la arribada la policía y el celador de sanidad del puerto de llegada debian acercarse para tomar razón del lugar de procedencia, de la situación de la embarcación y, una vez realizados esos trámites, se autorizaba la siguiente visita, llamada de aspecto, con el médico para preguntar sobre la salud pública. La tercera visita, se ocupaba del reconocimiento interior, llevada a cabo por el médico y el celador, si el examen era satisfactorio se admitía en el puerto si no se le negaba la entrada. Los buques tocados pasaban al lazareto ordinario; los sospechosos y los sucios a uno de los lazaretos de observación, donde las personas tenian que cumplir la cuarentena y el expurgo, este se refiere a la desinfección de los efectos y las mercaderias.

Antes de finalizar este apartado y como unión con el siguiente hay que referirse a la clasificación de lazaretos, relacionados con el comercio, en tres clases: ordinarios, de observación y sucios. Los primeros, debian existir en todos los puertos que no tuviesen ni lazareto de observación, ni lazareto sucio. Estos lazaretos estaban destinados a los buques de patente tocada o cuando existiese duda, debido a un naufragio o persecución de enemigos. Hecho dimensionado por la importancia del tráfico marítimo en los puertos del océano Atlántico y en los del mar Mediterráneo. Sin embargo, una cuestión, es la de la habilitación de lugares para lazaretos, y otra, la de su construcción como tales tipologías arquitectónicas. 
Aunque el de Mahón, lazareto sucio, será tomado como modelo para otros proyectos ${ }^{20}$.

\section{LAZARETOS: DISEÑOS ACADÉMICOS}

Lo primero que se quiere subrayar es esa cualidad, de lo monumental arquitectónico, que caracteriza a otros diseños de edificios públicos y que se pretendía llevar también a los edificios pensados para la salud pública. Centros de extraordinario interés con una particular semántica científica condicionada por sus funciones relacionadas con el aislamiento ${ }^{21}$. Como veremos más adelante hay ejemplos que relacionan los lazaretos de curación con los llamados sanatorios, lugares destinados a sanar, en donde al aislar a los enfermos, se planteaban además de reducir los focos y su propagación, estudiar las condiciones de higiene, salubridad e igualmente el contacto con la naturaleza. Fuente de aire puro, porque en el campo y en el mar están las bases de un medioambientalismo de cura natural.

Otra cuestión a destacar, respecto a las fuentes documentales, es, como sus autores expresan en sus manuscritos, la percepción del problema y la necesidad de edificar lazaretos. También se lo plantea la Real Academia de Bellas Artes. Los proyectos, que guarda dicha institución, tienen una gran importancia. Son 13 proyectos ${ }^{22}$ que suman más de cuarenta planos, que se hallan en el Gabinete de Dibujos de la Real Academia de Bellas Artes de San Fernando de Madrid y en su Archivo-Biblioteca se guardan los informes facultativos de los proyectos arquitectónicos. Forman un relevante conjunto, imprescindible para conocer una síntesis de las ideas de la época acerca de la historia, evolución y concepción de los lazaretos. Tales manuscritos, también llamados memorias descriptivas, tienen un gran interés como monografías estudiadas y firmadas por sus autores. No obstante, debido a la concreción del tema, únicamente se transcriben algunos de los datos, que se consideran más ilustrativos para la exposición de las ideas.

20 Como se verá en el siguiente artículo con el mismo título que éste.

21 Santamaría Almolda, Rosario La tipologia hospitalaria española en la Real Academia de Bellas Artes de San Fernando (1814-1875), tesis doctoral dirigida por el Dr. D. José Enrique Garcia Melero, leida en la Universidad Nacional de Educación a Distancia, Madrid, 27 de junio de 2000 y publicada en formato micrográfico.

$2 \varepsilon$ En este estudio los que se analizan seguidamente y, en una segunda parte los Lazaretos diseñados por José Oriol Mestres (1841), Francisco Daniel Molina (1842), Francisco Morales Hernández (1844), Manuel Julián San Martín (1845), José Ramón Más (1854) y, otros proyectos ideados directamente para ser construidos y no para examen. 
Cronológicamente, el primero de la serie estudiada, corresponde a un Lazareto ideado por un discípulo de la Academia. Pedro Nolasco Ventura, nacido en Estella (Navarra) del que se toma como pórtico gráfico, la imagen que representa la Puerta de entrada del lazareto (lámina I). Además en el plano de la planta baja explica que fue uproyectado para las inmediaciones de Madrid, según asunto dado por la Real Academia de San Fernando en 2 de Noviembre de 1800, para la recepción de Maestro Arquitecto". Efectivamente en su expediente se hallan los documentos que nos informan de esa prueba. El seis de marzo de 1802, con veintiseis años, solicitó presentarse al examen de arquitecto ${ }^{23}$, además del proyecto, realizó y firmó en la Academia, como prueba, la referida Puerta de entrada del lazareto. Fue aprobado el treinta del citado mes.

Por otra parte, en la memoria facultativa, expresa la idea, que relaciona la construcción de lazaretos con el beneficio público a pesar de que «siempre se han mirado con tanta desidia que en España no tenemos ninguno que con razón se le pueda dar este nombre. Las miras de V. E. por la

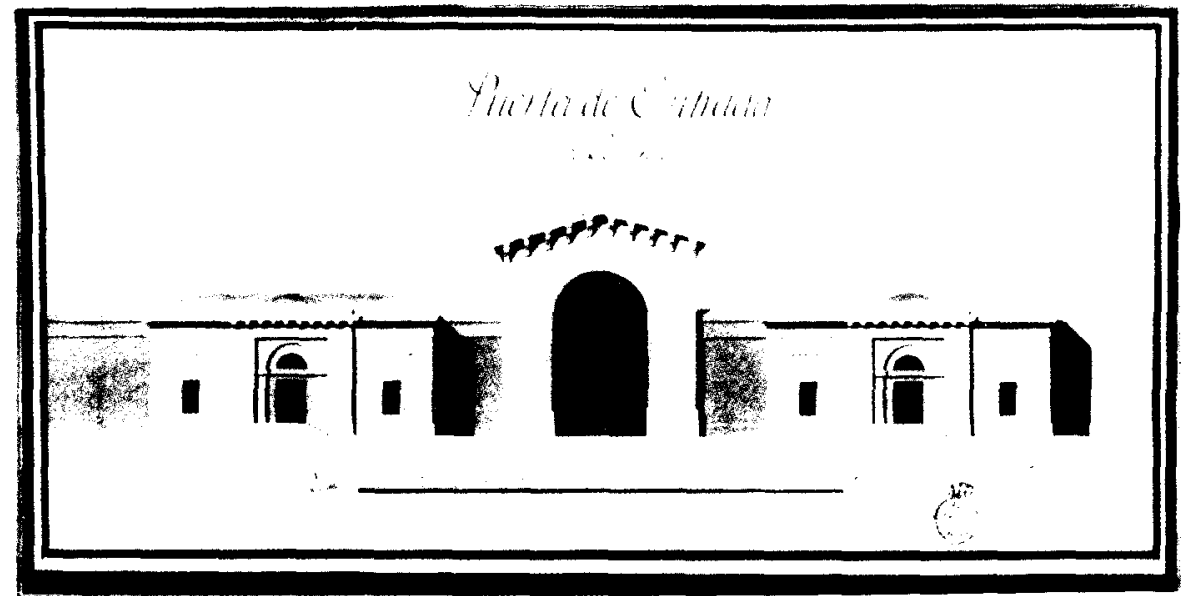

Lámina 1. Pedro Nolasco Ventura. Puerta de entrada. 1802. Academia de San Fernando. A-2627.

23 Con las bases y requisitos de la Real Orden de 29 de julio de 1801, que se exponen en Balsalobre García, J. M. "El aspirante a arquiterto y la Real Academia de Bellas Artes de San Fernando (1845-1855)" en Arquitectura y Ciudad en España de 1845 a 1998. I Jornadas de Arquitectura Histórica y Urbanismo. Cádiz, 3, 4 y 5 de junio de 1998. Coordinación y edición M. D. Antigüedad del Castillo-Olivares y J. R. Cirici Narvaez Universidad Nacional de Educación a Distancia, Universidad de Cádiz Servicio de Publicaciones, 2000, págs. 135-146. 
conservación de la salud pública y lo expuesta que se ha visto España entera a ser victima de la infección reciente de la Andalucia creo habrá dado motivo a pensar en este proyecto ... Es el Lazareto un edificio que sirve para custodiar por cierto tiempo las personas, caballerias, géneros, muebles, etc de quienes se tiene sospechas puedan conducir alguna enfermedad $u$ epidemia que reina en paises de a donde vienen ... no nos debemos desentender de proporcionar a aquellos infelices que vienen huyendo del contagio todos los socorros necesarios" ${ }^{24}$. Estas ideas, además de expresar la situación y el lenguaje de la época, muestran otra de las vertientes referidas a la movilidad y al comercio que justifican la necesidad de lazaretos.

Sabemos que el autor, en el año 1799 , había ganado el premio de 1 a $^{\text {a }}$ clase de arquitectura con plano de situación y cementerios para Madrid ${ }^{25}$. Conocía por tanto el lugar más adecuado para un lazareto, lo piensa para ubicarlo entre Chamartin y Hortaleza, es un lugar elevado. "Los vientos son moderados, sus aires secos y frescos, las aguas abundantes y dulces siendo las que vienen por este viaje las mejores que se beben en Madrid, sus vistas amenas y gratas, y su temperamento más frío que caliente, bastante fácil la provisión de abastos y libres (de los efluvios), tanto los pueblos ... como esta Corte» ${ }^{26}$. La solución en planta (lámina II) se organiza a partir de un primer volumen arquitectónico, que forma una gran puerta de entrada. A cada lado se unen los lienzos de la cerca de forma regular, rectangular. Dentro de ese espacio se distribuyen cinco grupos principales de edificios con patios y extensas zonas ajardinadas. Pensado para resolver el aislamiento entre edificios, la comodidad en cada uno de ellos y «la libre comunicación de ayres; unico remedio para que el contagio no se comunique de unos a otros". El eje de simetría marca la importancia tanto de los volúmenes construidos como de los espacios ajardinados. Destaca la sobriedad compositiva y ornamental de la puerta de entrada al lazareto, lámina I, que contrasta con la solución dada al edificio central, normalmente destinado a capilla. De ahí la importancia arquitectónica que se aprecia en el alzado (lámina III) con un desarrollado pórtico de orden gigante y lenguaje clasicista. La seriación de vanos se halla relacionada con la función y la necesidad de aireación y ventilación del lugar.

24 Pedro Nolasco Ventura. Memoria facultativa, Madrid 1802. AASF. Leg. 68-2/4.

25 Arbaiza, S., Ciruelos, A., Garcia, P., Heras, C., Perez, B. Catalogo de la Exposición Hacia una nueva idea de la Arquitectura. Premios generales de arquitectura de la Real Academia de Bellas Artes de San Fernando (1753-1831). Real Academia de Bellas Artes de San Fernando, Madrid, 1992.

26 Pedro Nolasco Ventura. Memoria facultativa, Madrid 1802. AASF. Leg. 68-2/4. 

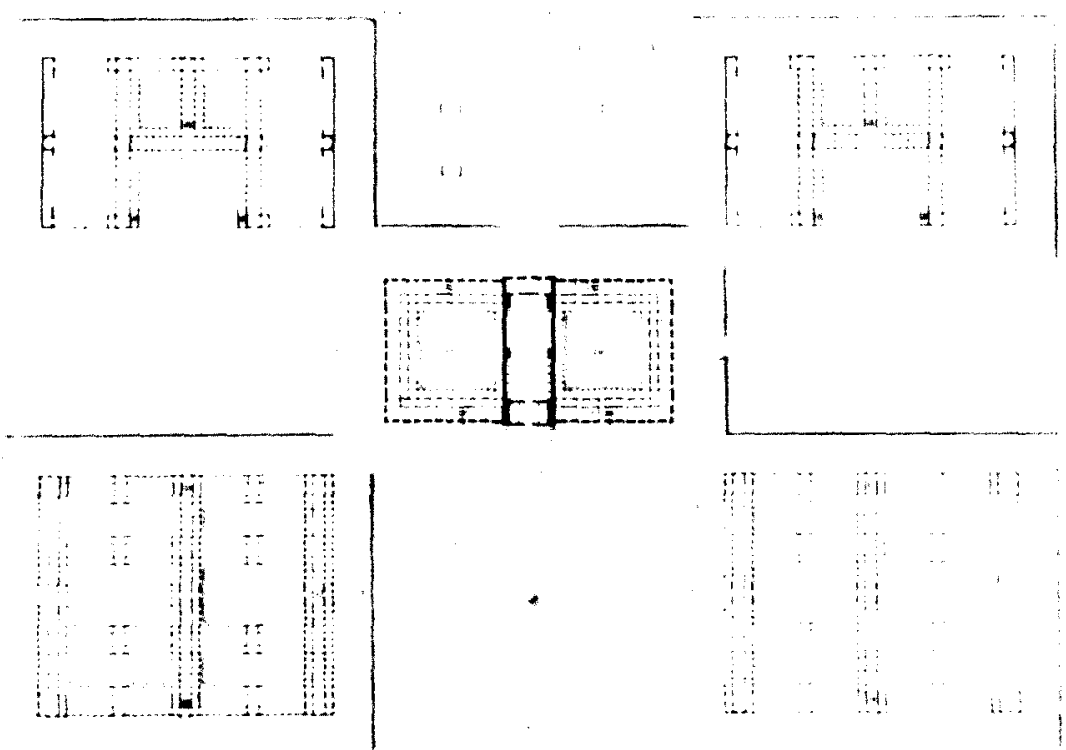

$\{z--1=2$

Lámina II. Pedro Nolasco Ventura. Planta baja. Academia de San Fernando. A-2624.

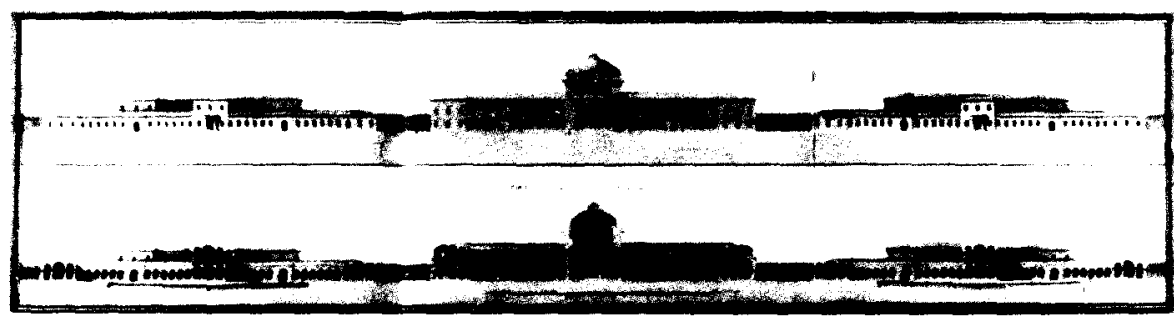

Lámina III. Pedro Nolasco Ventura. Fachada principal. Corte dado por las líneas ABCDEF de la planta. Academia de San Fernando. A-2626.

Dentro de la misma línea discursiva se pueden incluir seis proyectos de Lazareto para Madrid (1805) delineados los tres primeros por Fermín Gutiérrez, quien obtuvo el primer premio de $1 .^{a}$ clase de la arquitectura otorgado por la Academia de San Fernando ${ }^{27}$, y los otros por el autor del se-

Arbaiza, S., Ciruelos, A., Garcia, P., Heras, C., Pérez, B. op. cit. pág. 187. «Se proyectarán tres Lazaretos separados para Madrid, indicando en un plano geográfico de esta población los 
gundo, Miguel Antonio de Marichalar. Tanto el uno como el otro, aportan en el proyecto un Plano Geogrático de la Villa y Corte de Madrid y sus inmediaciones. Aquí se adjunta la copia del diseñado por Fermín Gutierrez (lámina IV), aunque también interesa la aportación del segundo. Gutierrez delinea los lazaretos, destaca, a la derecha del plano, la bella traza, debajo de la rosa de los vientos. Hay que subrayar respecto a Marichalar la idea, que relaciona la necesidad de los lazaretos con el grave problema de la fiebre amarilla en 1800 en Cádiz. La cuestión a resolver no era únicamente la de establecer las medidas para cerrarla sino también la de evitar su propagación, como se ha expuesto anteriormente.

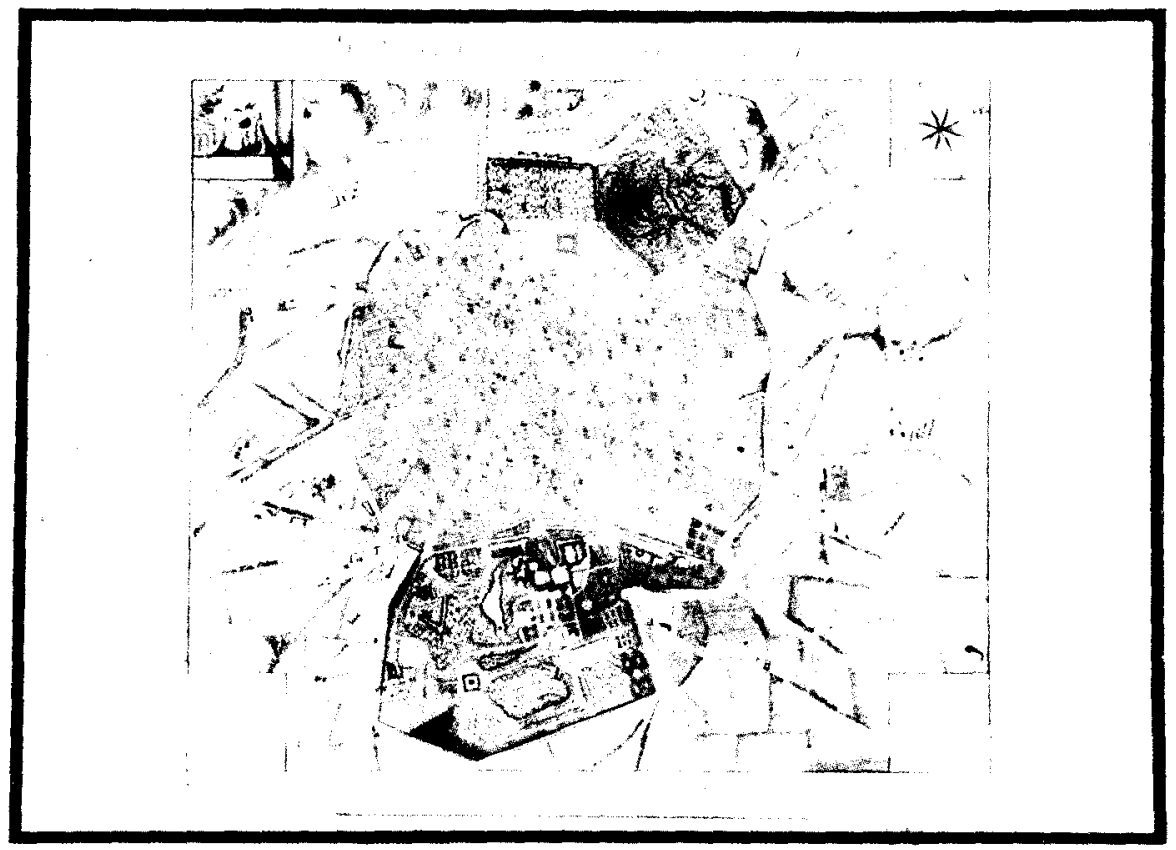

Lámina IV. Plano Geográfico de la Villa y Corte de Madrid y sus inmediaciones. Academia de San Fernando. A-2628 (a) bis.

parages donde se situen en las inmediaciones de ella: 1. que sirva de observación para los objetos y efectos procedentes de los paises contagiados con entera separación de los sexos, y de los que han salido de dichos pueblos quince dias antes declarado el estado del contagio, y de los procedentes de los pueblos situados a diez leguas de los ya declarados en dicho estado de contagio; el 2." para Hospital de apestados, y que reuna todas las ventajas convenientes para aislar el contagio, y evitar el que se difunda en los puebios inmediatos; y el $3 .^{\circ}$ para expurgar todos los efectos y géneros procedentes de paises extrangeros". 
Tanto Fermín Gutierrez ${ }^{28}$ como Miguel Antonio de Marichalar ${ }^{29}$ ilustraron el plano de cada uno de los proyectos con la explicación de su destino. El primero: "Lazareto destinado para observación de los objetos y efectos procedentes de los paises contagiados con entera separación de los dos sexos y de los que han salido de los pueblos quince días antes de haberse declarado el estado de contagio y de los procedentes de los pueblos situados a diez leguas de los ya declarados en dicho estado conforme al problema que en primer lugar ha propuesto la Academia de San Fernando en su edicto de primero de enero de este año". El proyecto de Fermín Gutierrez se dispone en la línea de aislar, totalmente, el recinto exterior y, en el interior, separar las construcciones. Diseña cada una de las áreas del recinto, señaladas por su función.

En el plano de la planta baja se da una correspondencia formal entre el octógono central y la cerca, que delimita el recinto exterior. El octógono interior, además del espacio abierto, tiene diseñado un cuadrado, donde se halla inscrita la capilla con solución en planta de cruz griega. Lugar abierto con construcciones destinadas a lugares comunes como baños, salas de fumigación lavaderos y cocinas. El arquitecto las enlaza con sendas galerías que comunican con los pabellones de los contagiados. Contempla la construcción de un foso que impida el acceso o la salida sin un control, por ello solamente diseña una entrada. Desde la que se ingresa en el vestíbulo, donde ubica la portería y el cuerpo de guardia. Sobresale el edificio religioso y el sistema de pabellones dormitorios.

Es el eje de simetría el que determina la regularidad compositiva y la correspondencia de las dos partes, así como la indicación de una separación de sexos ${ }^{30}$. También aislada, y en la parte posterior del mencionado eje, destaca la edificación de forma rectangular con amplio patio, para el

28 Fermín Gutierrez fue opositor en los Concursos Generales de Premios de los años 1799 , 1802 y 1805. el 27 de mayo de 1806 la Comisión de Arquitectura estudio y aprobó un proyecto de Universidad Literaria para construirla en Salamanca y el 6 de julio de 1806 fue aprobado de arquitecto. AASF. Leg. 68-3/4.

29 En el expediente de Miguel Antonio de Marichalar, discípulo de la Academia, se halla la certificación de la práctica arquitectónica firmada por el académico, Ignacio Haan, Madrid 2 de diciembre de 1807 . En esa fecha solicitó presentarse al título de arquitecto, sus estudios se habían realizado durante nueve años en la Real Academia, sus méritos haber obtenido dos premios generales en Arquitectura, el 1. "en tercera clase en el año 1802 y el 2." de primera en 1805. AASF. Leg. 68-3/4. Ignacio Haan lo he estudiado en Catálogo de proyectos de académicos, arquitectos $y$ maestros de obras alicantinos, censuras de obras y otras consultas en la Academia de San Fernando (1760-1850), Alicante, ed. Instituto Alicantino de Cultura Juan Gil-Albert, Diputación de Alicante, corregidas pruebas de imprenta, pero no se han establecido las relaciones con los discipulos de la Academia como Miguel Antonio de Marichalar.

30 Santamaria Almolda, R. ob. cit. 
personal sanitario, médicos, oficiales de sanidad, capellanes, otros empleados y la hostería. Su correspondencia se aprecia en el plano del piso principal (lámina V) con la explicación de cada uno de los usos, entrada pórtico, escalera, diferentes cuartos para el guarda, el teniente y los "quarentenistas", cocinas, servicios etc.

La lámina VI corresponde a las «plantas geométricas que manifiestan el proyecto Lazareto de observación para los objetos y efectos procedentes de los paises contagiados que se ha de construir a las inmediaciones de Madrid". Miguel Antonio de Marichalar idea su proyecto dentro de los valores académicos de regularidad clasicista. Elige como figura geométrica predominante la cuadrada y la rectangular, forma que permite diseñar con facilidad las trazas de las construcciones e igualmente los patios y jardines. No obstante, reserva el lugar central para la capilla y el teatro anatómico, para los que busca la óptica, que aporta la forma circular. La planta del piso bajo se resuelve con cuatro cuadrados independientes, como alas claustrales de grandes patios clasicistas con un repetido juego de unas particulares galerías.

Elementos, que también utilizó Fermín Gutierrez (lámina VII), rio solamente se disponen por su belleza sino más bien porque permiten la circu-

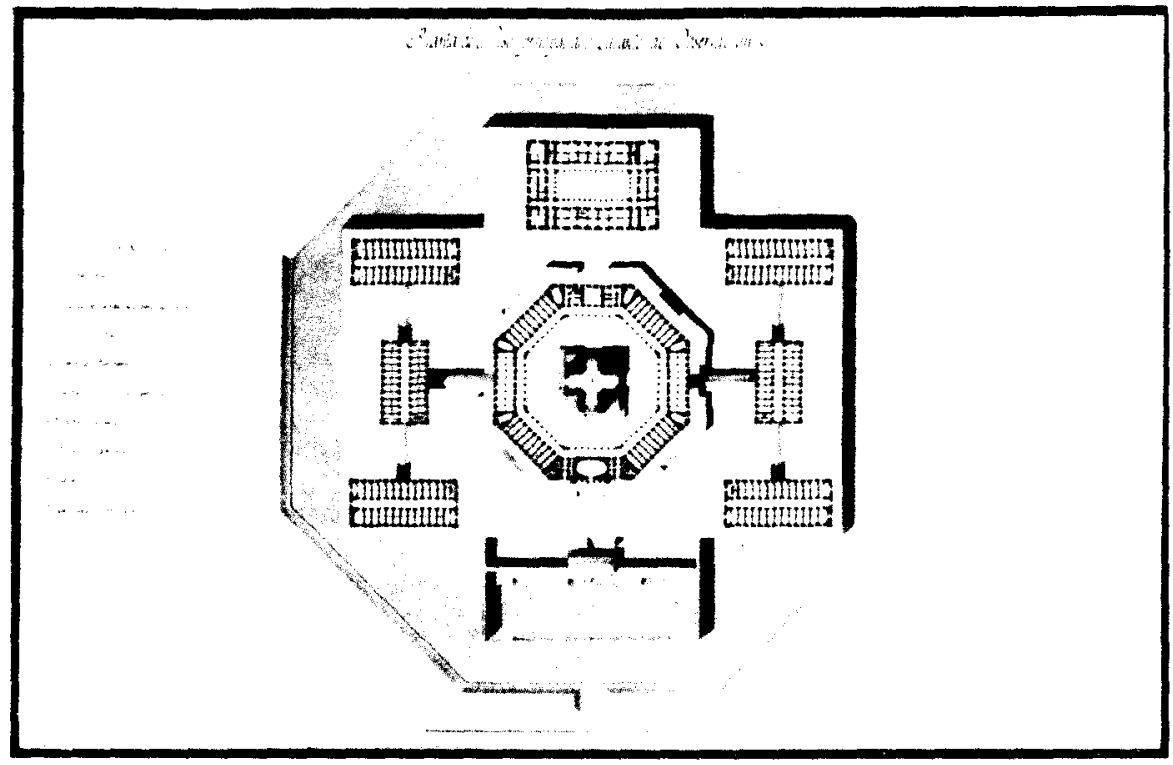

Lámina V. Fermin Gutierrez. Planta principal de un Lazareto para Observación. Academia de San Fernando. A-2630. 


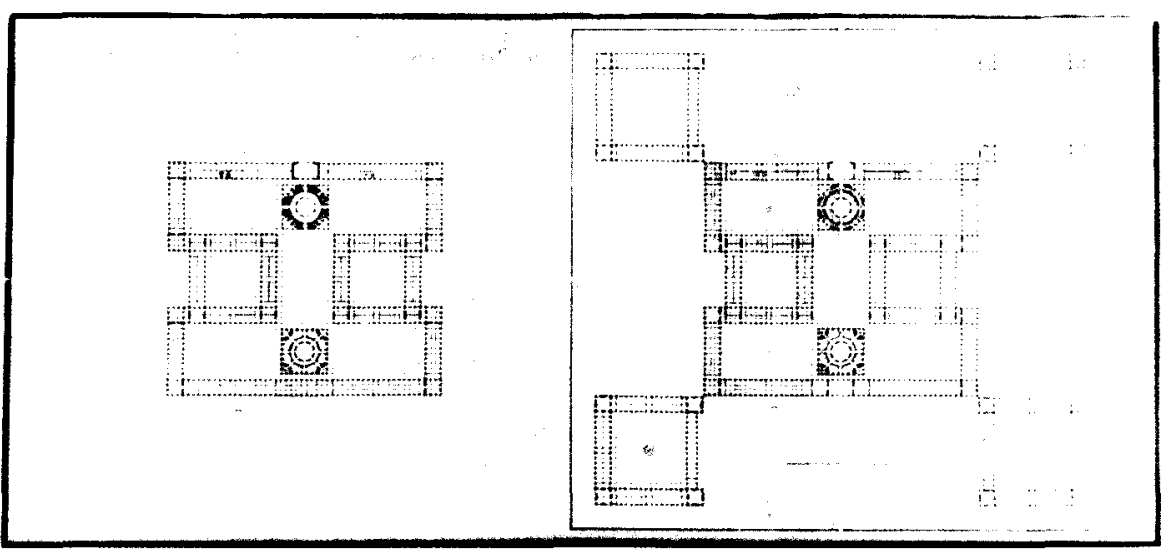

Lámina Vi. Miguel Antonio de Marichalar. Plantas del piso bajo y del principal. Academia de San Fernando. A-2637.

lación del aire, la separación y al mismo tiempo la comunicación. Destaca el recurso a la seriación de vanos como se aprecia en el alzado, sin una jerarquización del piso principal. Sin embargo, sobresale con fuerza el bello pórtico, la cúpula y las trazas de sendas fuentes, que conjugan una buscada solución historicista, monumental de lectura clasicista.

Los segundos proyectos de Fermín Gutiérrez y Miguel Antonio de Marichalar siguen un mismo enunciado «Planta de un Lazareto destinado para hospital de contagiados con todas las oficinas pertenecientes a su destino conforme al problema que en $2 .^{\circ}$ lugar ha propuesto la Real Academia de San Fernando, en sus edictos de $1 .^{\circ}$ de enero de 1805». Con detallada explicación, el primero, en el plano de la planta baja (láminas VIII), señala el edificio destinado a teatro anatómico, que se coloca en la parte posterior del eje central y posterior a la capilla. Se trata de un lazareto cercado de forma regular. Cuadrada es la figura que, junto con las circulares del centro, delinea el arquitecto para repetir entre sus lados espacios abiertos y también a cada lado del eje de simetría. Tanto en la parte delantera como en la posterior de la cerca, se disponen dos áreas que corresponden a sendos patios de grandes dimensiones, para ventilación y paseo.

Una línea semejante, es la diseñada por Marichalar, en la planta del proyecto de un hospital de apestados, lámina IX. Pensado para su construcción en las inmediaciones de Madrid, y con una solución de estudiada regularidad geométrica. Desarrolla una lectura centralizada, circular, con pabellones radiales organizados dentro del octógono y bellos jardines. El 


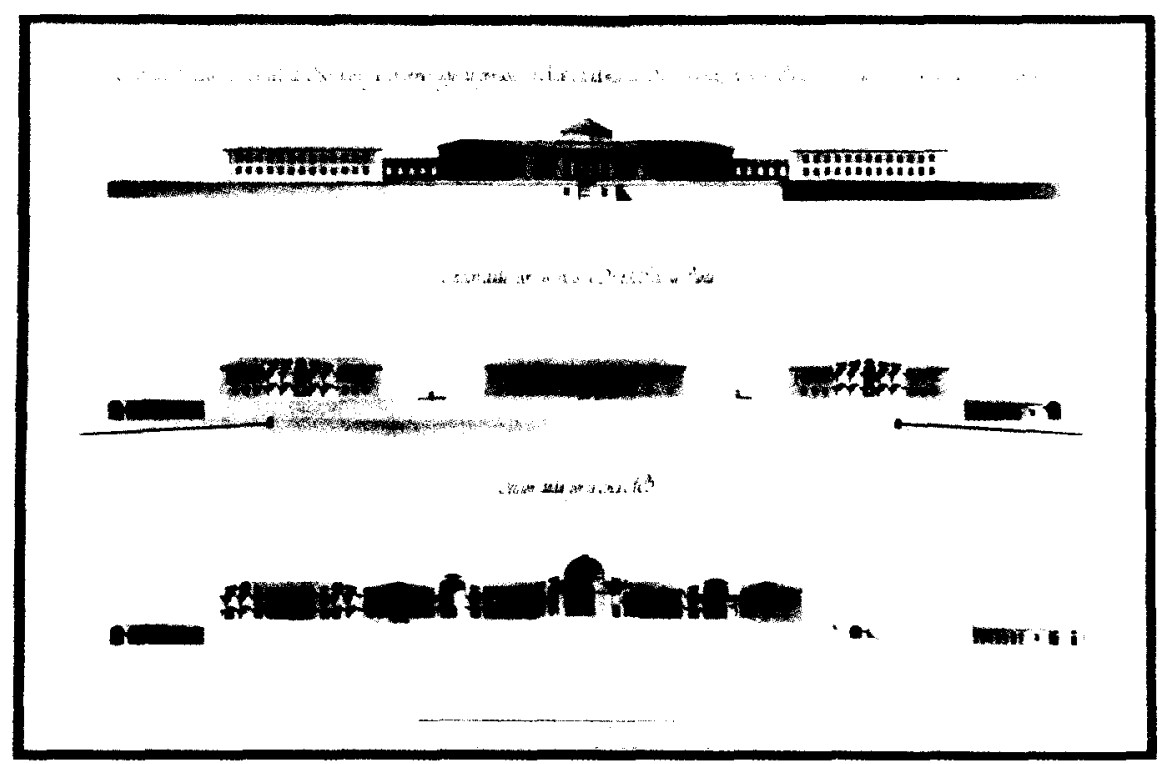

Lámina VII. Fermin Gutierrez. Fachada principal del Lazareto de Observación. Sección dada por las líneas CDEF.FG de su planta. Sección dada por la línea $A B$. Academia de San Fernando. A-2631.

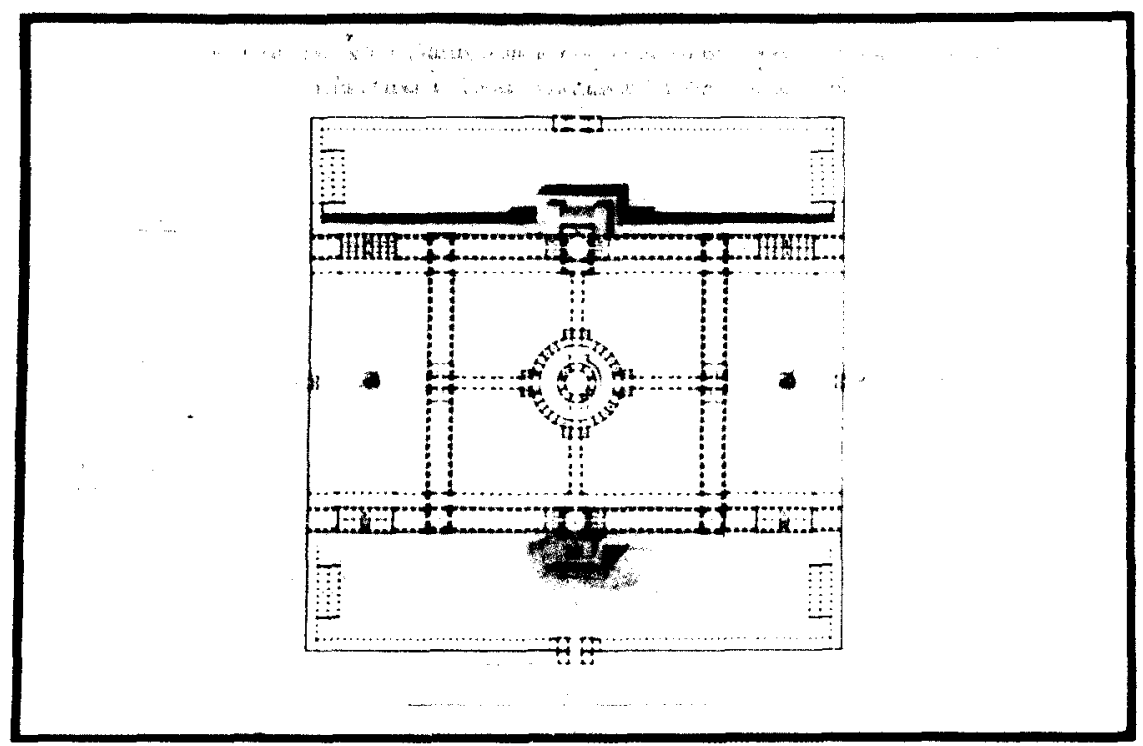

Lámina VIII. Fermín Gutierrez. Planta de un Lazareto para Hospital de contagiados. Academia de San Fernando. A-2632. 
vestíbulo, la oficina para recibir a hombres y a mujeres y los guardias oficiales, se ubican en el eje AB. A la derecha del plano son las áreas reservadas para los hombres, y a la izquierda las determinadas para las mujeres. Destacan los cuatro patios delineados en los apéndices y también la disposición, paralela al eje de simetría, de los jardines laterales, donde el arquitecto dibuja la cerca. Fermín Gutierrez en la lámina $X$ presenta un sobrio diseño clasicista, que acentúa claramente con el recurso a la centralidad determinada por el recurso al órden clásico del monumental pórtico de la fachada principal. También dispone un desarrollado zócalo y utiliza las seriaciones de vanos con un ritmo repetido de lleno vacío, determinado por la tipología. Igualmente utilizado por Marichalar, pero que delinea con un alzado de tres pisos, con una gran portada de lenguaje clasicista.

El tercer modelo de Lazareto, lo resuelven tanto Fermín Gutiérrez como Miguel Antonio de Marichalar, con la idea marcada por la Real Academia de San Fernando y que cada uno explica en la planta de un Lazareto destinado para expurgar todos los géneros y efectos procedentes de paises extranjeros. La lámina XI nos muestra un cerramiento exterior, que en los lados mayores dispone de las galerias. El arquitecto traza el edificio a partir de una forma geométrica, cercana a la tipología teatral, pero en el se-

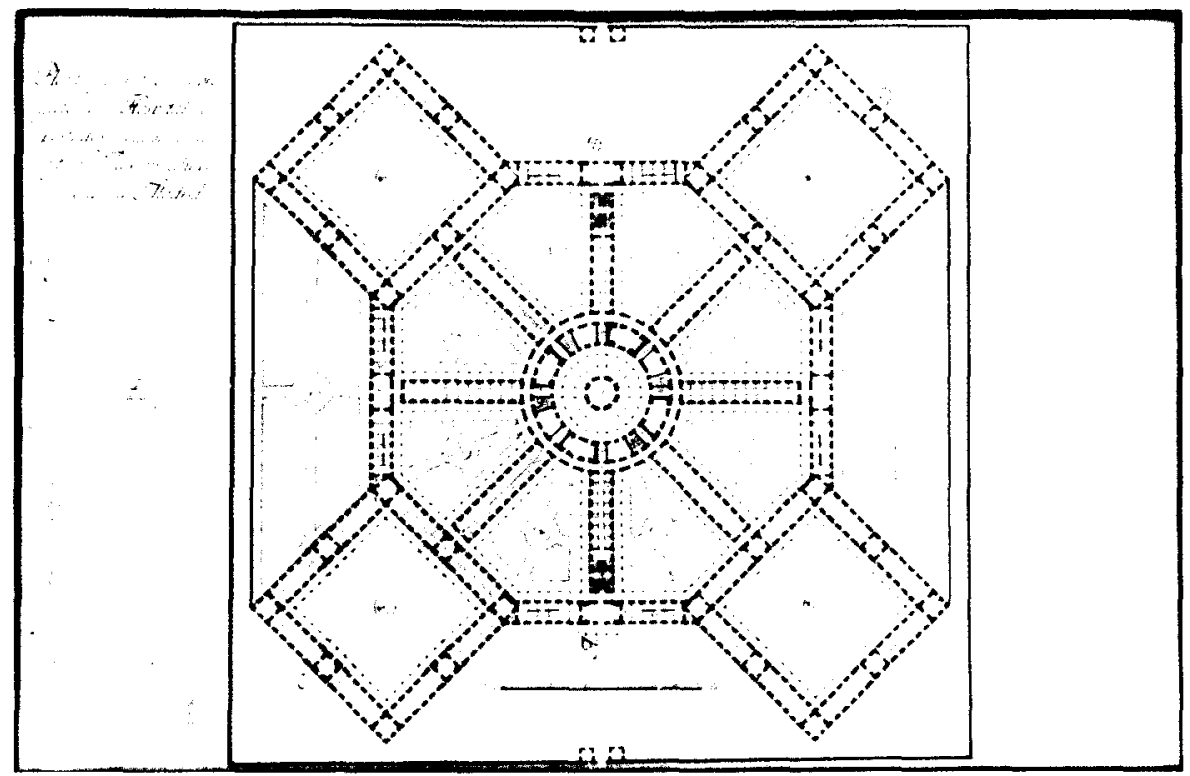

Lámina IX. Miguel Antonio de Marichalar. Planta geométrica de un Hospital de apestados. Academia de San Fernando. A-2641. 


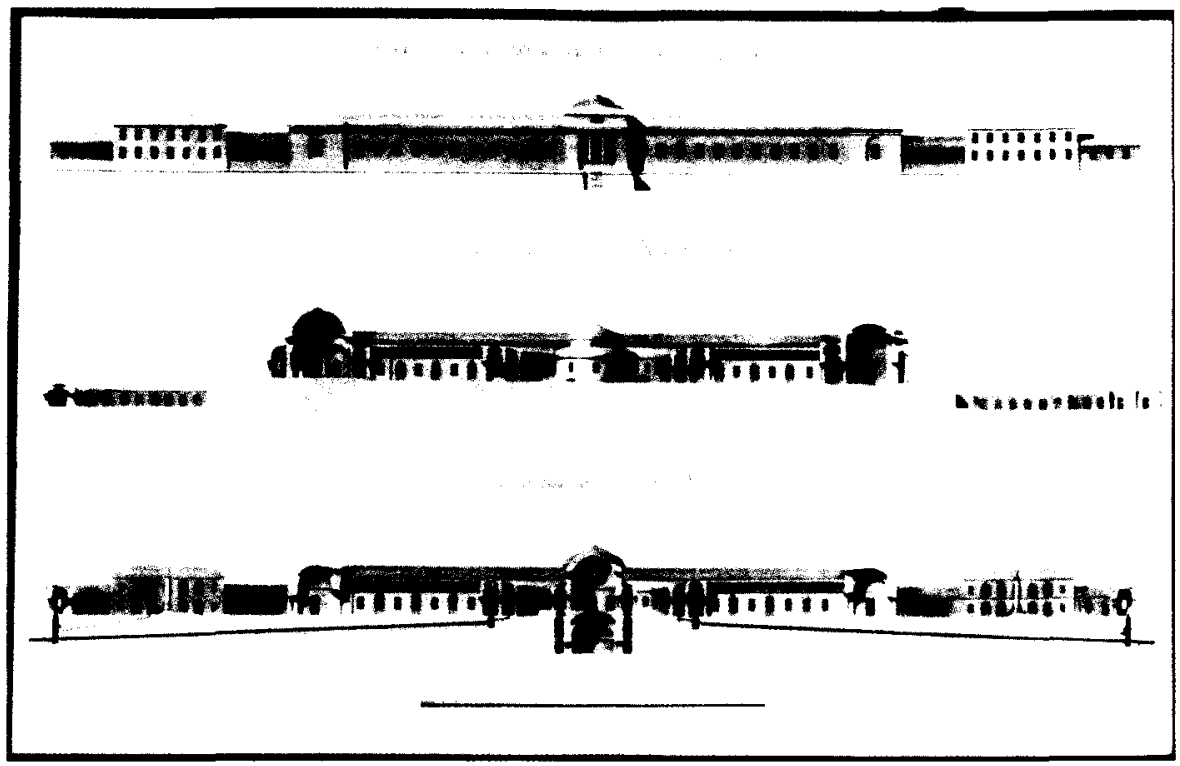

Lámina X. Fermin Gutierrez. Fachada principal de un Lazareto para Hospital de contagiados. Sección dada por las linea ABEFG de su planta. Sección dada por la linea CMNPQD. Academia de San Fernando. A-2633.

micírculo añade unas desarrolladas alas que a manera de galerias forman la más grande área para construir, rodeada de dos grandes jardines y pequeños volumenes construidos en las esquinas y logicamente el del cuerpo de guardia y otros servicios. Dentro de esa buscada regularidad compositiva Miguel Antonio de Marichalar proyecta su Lazareto para expurgar los efectos y géneros en dos alturas, pero también son los grandes patios, como se aprecia en la lámina XII, los que organizan la delineación del proyecto. Elige la ortogonal con las figuras geométricas rectangulares y cuadradas, que son elementos determinantes en las plantas. Igual que el proyecto anterior parte de esa idea necesaria de aireación y separación con los grandes jardines que se abren a los volúmenes construidos.

Lógicamente en esta serie de diseños, además de apreciar la monumentalidad de los edificios, y particularmente sus grandes dimensiones, incluso en los alzados de los proyectos de Lazaretos destinados a expurgar los efectos y géneros procedentes de paises extranjeros, lámina XIII, se apunta, a una situación socio-sanitaria relacionada con el grave problema de la fiebre amarilla, que apareció el año 1800 en Cádiz, se trataba de salvaguardar las ciudades, también Madrid y la Corte. 


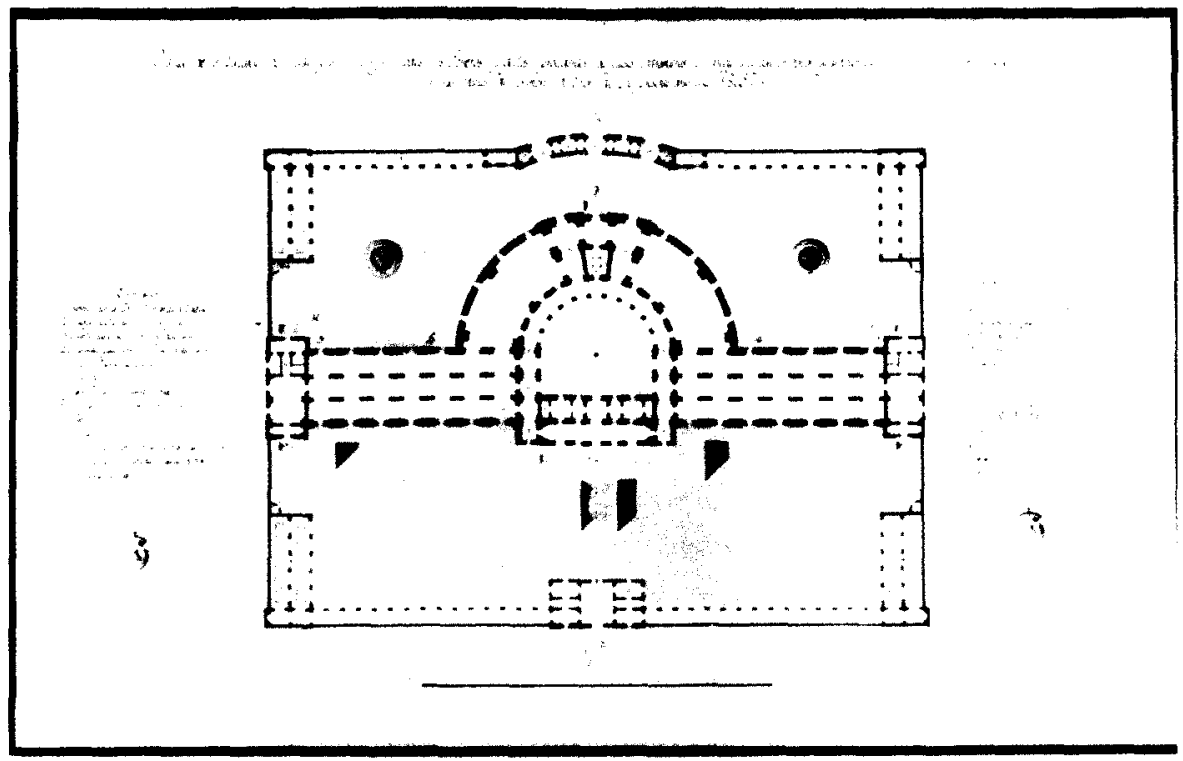

Lámina XI. Fermín Gutiérrez. Planta de un Lazareto para expurgar géneros y efectos. Academia de San Fernando. A-2634.

En el año 1826, otro proyecto, muestra la comentada necesidad del edificio lazareto. Formado por el madrileño, José Paris, discípulo de la Academia, que presentó, un singular diseño de Lazareto en alto, para la primera prueba del examen de arquitecto ${ }^{31}$. También superó los demás ejercicios y el 4 de junio de 1826 fue aprobado. Muy interesante es, la exposición escrita como memoria facultativa ${ }^{32}$ e igualmente, la disposición

31 José Paris. En su expediente se halla una copia del 30 de marzo de 1826 en el que se refiere a lo determinado por la Comisión de Arquitectura en su junta del 9 de ese mes «ha examinado el proyecto de un Lazareto distribuido en distintos pabellones para el mejor uso, comodidad ventilación y apartamiento de las diferentes clases de enfermedades que allí pueden reunirse y la presenta el discipulo don José Paris natural de Madrid y edad de 26 años con objeto de aspirar a los ejercicios de Mro Arquitecto «. AASF. Leg. 68-3/4.

32 José Paris expone puntos que hay que destacar porque aportan otras ideas sobre el Lazareto como por ejemplo lo que sigue "Aquellas obras que se destinan al bien de la humanidad han sido ... las más dignas de atención de todos los Gobiernos ... edificios destinados a proteger a los infelices y a asegurar la salud pública ¿Pero estos edificios presentan generalmente todas las comodidades anexas a su fin? De ninguna suerte los más de ellos construidos para fines diversos, sirven muchas veces para exasperar a aquellos mismos que debian tener en ellos algún alivio.

En efecto, el navegante por tanto tiempo privado de la tierra donde respira y vive con libertad, cansado de las penalidades de la mar, cuando ya va a finalizar su pesada navegación es obliga- 


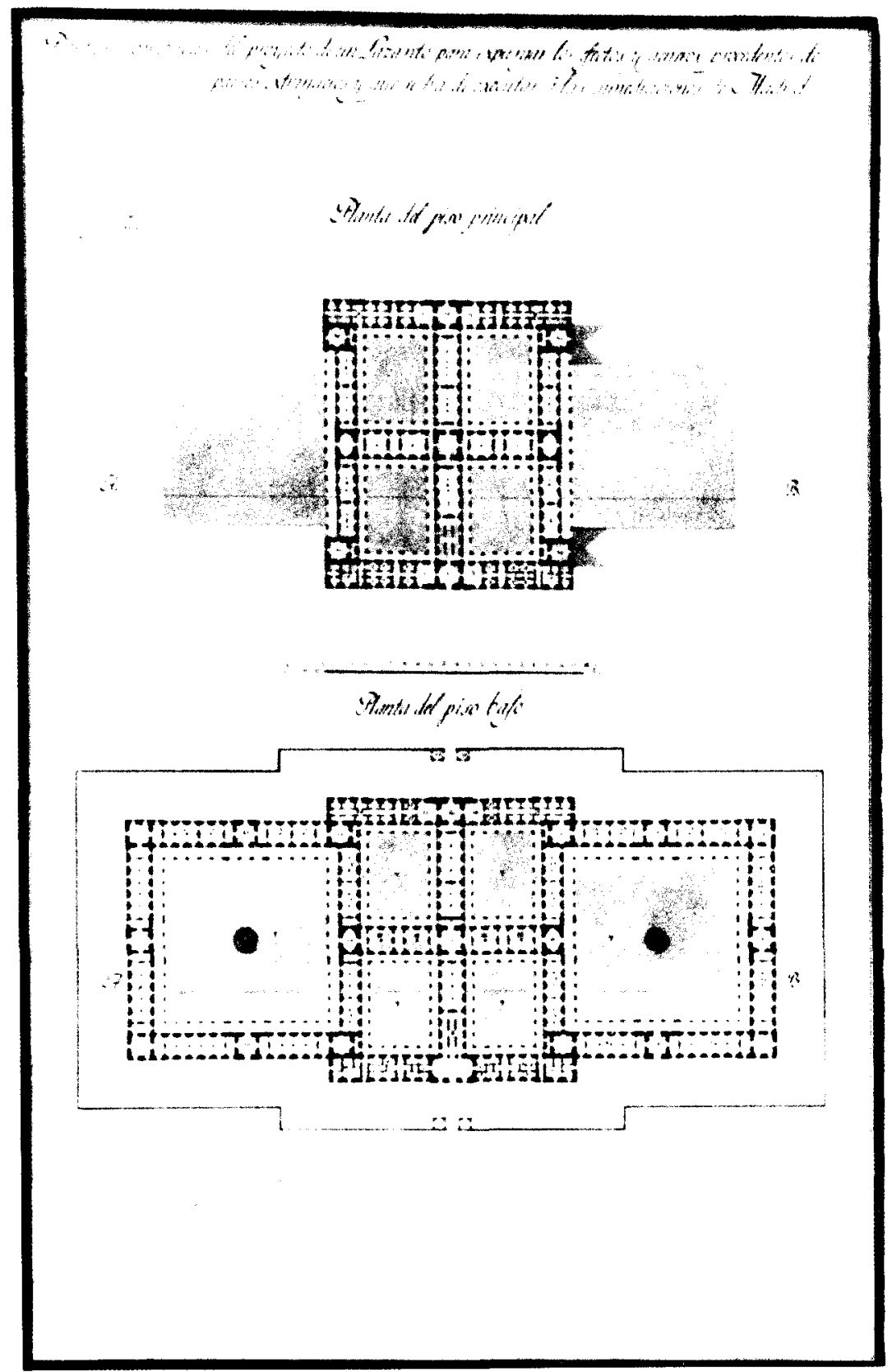

Lámina XII. Miguel Antonio de Marichalar. Plantas geométricas de un Lazareto para expurgar efectos y géneros, piso principal y bajo. Academia de San Fernando. A-2639. 

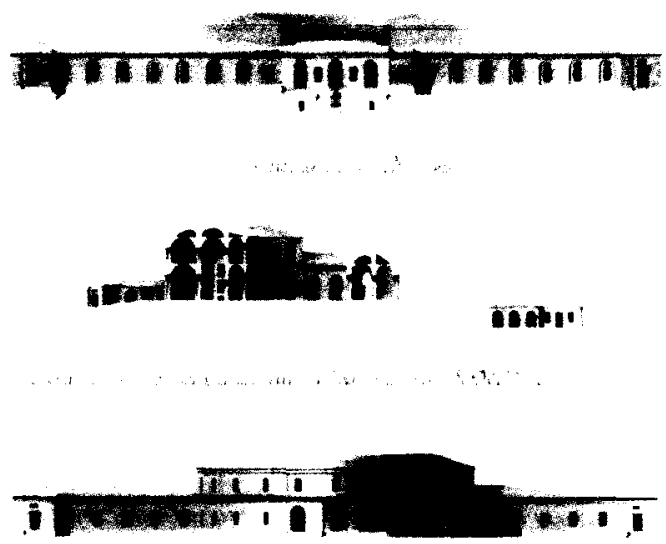

Lámina XIII. Miguel Antonio de Marichalar. Alzados geométricos de un Lazareto para expurgar efectos y géneros. Fachada de las accesorias. Sección por la línea AB. Fachada principal. Academia de San Fernando. A-2640.

que París presenta en su diseño, porque aunque dispone galerías para espacios de comunicación, la realidad es que, él, los explica como pabellones separados (A B C D E F), cada uno con su correspondiente patio. El planteamiento del lazareto ha sido analizado y forma parte de la idea de aislar en pabellones a "los apestados de los de observación, y a estos de los convalecientes; el considerable número de ventanas situadas bastante distantes del pavimento o suelo, es suficiente ventilación para cada sala, $y$ de esta suerte dispuesta no sirven de incomodidad alguna a los enfermos aunque el número de individuos en cada una de estas salas no deberá pasar a lo sumo de 20, de donde resulta que el aire está menos expuesto

do a encerrarse en una cárcel las mas veces, donde no sólo pierde su libertad, sino su existencia también. Esto es cabalmente lo que sucede en la mayor parte de los Lazaretos que existen en Europa. Estos edificios de tanta utilidad al género humano, si están bien ordenados, suelen ser la sepultura de millares que no sintiéndose ni remotamenie tocados de la peste, la reciben en ellos; o si la tienen, su convalecencia suele ser más peligrosa que la enfermedad misma. Movido por de estas reflexiones me determiné a idear un lazareto, disponiéndole en la forma que le presento a V.A. el cual creo tenga las mayores comodidades y se requieren para el fin a que se destina como igualmente su aspecto, la mayor sencillez". Memoria facultativa, Madrid, 25 de febrero 1826. AASF. Leg. 68-3/4. 
a infestarse. Sin embargo se pueden construir, para mayor abundamiento, ventiladores en los ángulos. En cada pabellón se pueden igualmente destinar varias piezas para un capellan, un botiquín y para otros usos de necesidad, ${ }^{33}$.

El arquitecto informaba que el lazareto tenía mil doscientos pies de fachada por mil trescientos de fondo y se podian albergar a mil enfermos con comodidad. Respecto a la situación, aunque no indicaba el lugar si mencionaba el norte y en un lugar elevado, "que aislado de la tierra firme fuese abundante igualmente en sanas aguas, presentando además seguridad a los buques" ${ }^{34}$. Este hecho se relaciona con la idea de un lazareto en puerto de mar. En la planta (lámina XIV) se aprecia la delineación de una cerca rectangular unida a la de figura semicircular, que en realidad se trata de galerías y porticada, abierta a la capilla (lámina XV). Todas ellas ideadas para poder pasear a cubierto, aunque también se disponen entre ellas las zonas ajardinadas. Asimismo proyecta una casa de baños, lavaderos y grandes almacenes. Es muy bella la solución (lámina XV), bien resuelta, se aprecia claramente en el alzado de signo clasicista y con una perfecta composición aislada de la capilla.

Antes de finalizar, no se trata de hacer una síntesis del tema, sino más bien de señalar, a manera de conclusión que, como otras arquitecturas, la del lazareto nace para cumplir una función. La idea de construirlo marcha paralela a la aparición y extensión de focos pestilenciales, que, desde los primeros tiempos, era necesario, cercar. Sin embargo, cuando se desataba una epidemia, si no había un lazareto cerca, se ocupaban casas de campo o edificaciones fuera de la población. Esa era una de las realidades, que se trataba de resolver con los medios disponibles y la otra más teórica, concernía a los proyectos arquitectónicos. Respecto a la tipología tanto la síntesis como otras comparaciones arquitectónicas se exponen en la segunda parte como ya se ha comentado.

33 Ibidem.

34 Ibidem. 


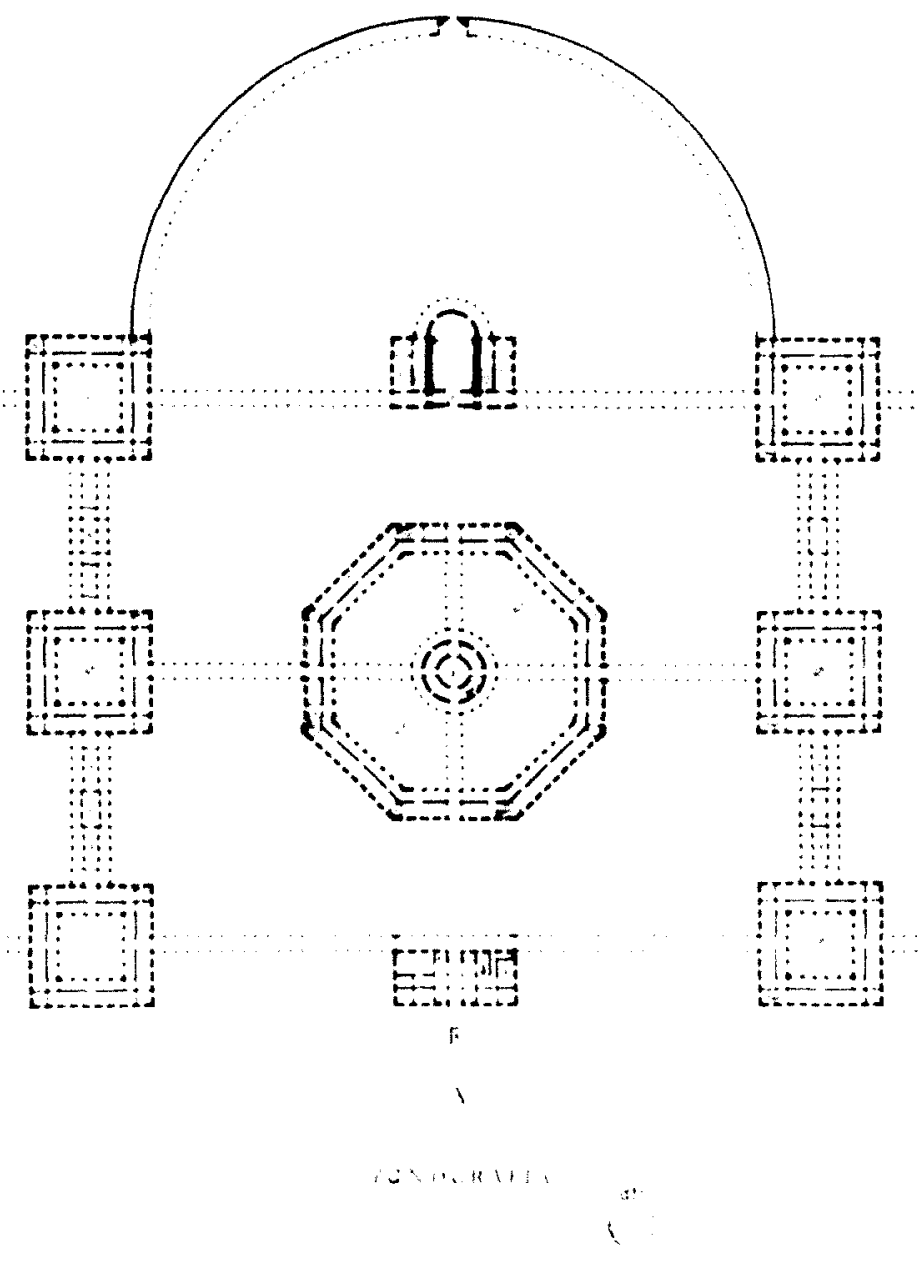

Lámina XIV. José Paris. Ignografia de un lazareto. Planta 1826. Academia de San Fernando. A-2643. 


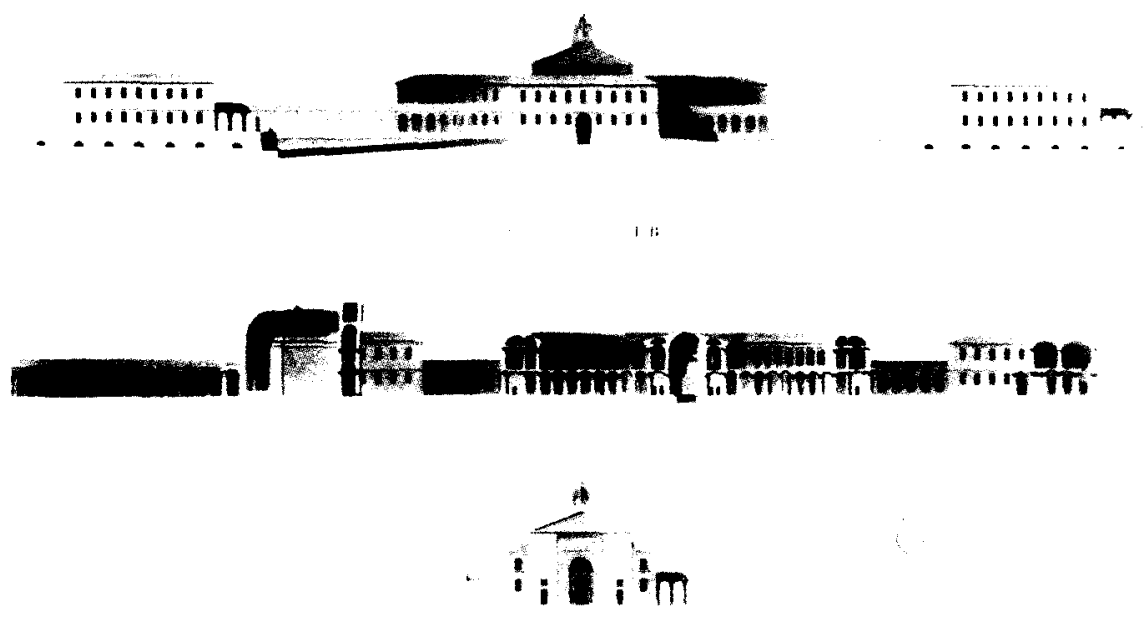

Lámina XV. José Paris. Ortografía de un lazareto. Fachada principal. Sección dada por la línea $A B$ de la planta. Fachada de la capilla. Academia de San Fernando. A-2644. 